CLINICAL STUDY

\title{
Plasma pancreatic polypeptide response to secretin
}

\author{
Maddalena Peracchi, Rosalia Tagliabue, Maurizio Quatrini and Eugenio Reschini ${ }^{1}$ \\ Istituto di Scienze Mediche dell' Università degli Studi, and ${ }^{1}$ Servizio di Medicina Nucleare, IRCCS-Ospedale Maggiore, Milano, Italy \\ (Correspondence should be addressed to M Peracchi, Istituto di Scienze Mediche, Padiglione Granelli, via F. Sforza 35, 20122 Milano, Italy)
}

\begin{abstract}
Objective: Intravenously administered secretin stimulates pancreatic polypeptide (PP) release in patients with endocrine enteropancreatic tumors, but data in patients with nontumorous disorders are controversial. Therefore, we aimed to evaluate the plasma PP pattern after secretin administration in healthy subjects and in patients with gastroduodenal diseases investigated for recurrent ulcer disease and/or hypergastrinemia.

Methods: Synthetic secretin was given as an intravenous bolus $(2 \mathrm{U} / \mathrm{kg})$ in ten patients with Zollinger Ellison syndrome, ten with duodenal ulcer, ten with atropic gastritis and ten healthy volunteers. Blood samples were taken before and at regular intervals for $30 \mathrm{~min}$ after secretin injection. Plasma PP and gastrin levels were measured by radioimmunoassay.

Results: Secretin promptly and significantly $(P<0.01)$ increased PP plasma levels in all groups of subjects without any differences in peak values. There were no significant correlations between PP and gastrin plasma levels.

Conclusions: Secretin at pharmacological doses is a powerful stimulus for PP release.
\end{abstract}

European Journal of Endocrinology 141 47-49

\section{Introduction}

In patients with Zollinger Ellison syndrome (ZES) intravenously administered secretin induces a paradoxical rise in circulating gastrin levels (1). Moreover, in a series of 26 ZES patients Rigaud et al. (2) found that secretin infusion significantly increased plasma pancreatic polypeptide (PP) levels, and considered this response was also paradoxical since it was abolished by gastrinoma excision. Similar results have been reported in patients with PPomas (3). However, conflicting data have been found when secretin was administered to healthy subjects and to patients without evidence of endocrine enteropancreatic tumors. Indeed, preliminary studies showed that extractive secretin (Boot's secretin) was a potent releaser of PP in humans (4), but it was claimed that impurities of this crude extract could mediate the secretin effect (5), as slow infusions of purified secretin failed to consistently stimulate PP release in normal subjects and in duodenal ulcer patients (2). On the other hand, Glaser et al. (6) demonstrated that both purified and Boot's secretin, given as an i.v. bolus of $2 \mathrm{U} / \mathrm{kg}$, induced significant PP responses in healthy subjects. Theoretically, the availability of synthetic secretin should allow clarification as to whether this peptide effectively stimulates PP release in humans, although in the two studies so far performed opposite results have emerged in normal subjects $(7,8)$. Therefore, we aimed to evaluate the PP plasma pattern after a standard i.v. bolus $(2 \mathrm{U} / \mathrm{kg})$ of synthetic secretin in ZES patients and, for comparison, in healthy subjects and in patients investigated for recurrent ulcer disease or hypergastrinemia, who eventually were found to have Helicobacter pyloriassociated duodenal ulcer or atropic gastritis.

\section{Subjects and methods}

The secretin test was performed in 10 patients with ZES ( 4 men and 6 women, aged 39-72 years, mean age 54), 10 patients with duodenal ulcer ( 5 men and 5 women, aged 38-72 years, mean age 55), 10 patients with atropic gastritis ( 1 man and 9 women, aged $37-76$ years, mean age 57$)$ and 10 healthy volunteers ( 4 men and 6 women, aged 27-65 years, mean age 41 ). The study was approved by the local ethics committee.

Table 1 summarizes the main data on gastrin plasma levels in the four groups of subjects. ZES was diagnosed according to the established criteria (1); in all patients the secretin test resulted in a rise in gastrin levels greater than $200 \mathrm{ng} / \mathrm{l}$. In four patients gastrinoma was a component of multiple endocrine neoplasia type I (MEN I) syndrome. All duodenal ulcer patients had evidence of Helicobacter pylori infection and showed normal fasting gastrin levels that did not change after 
Table 1 Plasma gastrin and PP responses to an i.v. bolus of secretin $(2 \mathrm{U} / \mathrm{kg})$ in healthy subjects and in patients with duodenal ulcer, ZES and atropic gastritis. Data are means (S.E.M.), with the exception of gastrin data in patients with ZES and atropic gastritis which are median and range.

\begin{tabular}{|c|c|c|c|c|c|}
\hline \multirow[b]{2}{*}{ Subjects } & \multirow[b]{2}{*}{ No. of cases } & \multicolumn{2}{|c|}{ Gastrin (ng/l) } & \multicolumn{2}{|c|}{ PP (pmol/l) } \\
\hline & & Basal & Peak/nadir & Basal & Peak \\
\hline Controls & 10 & $59(6.0)$ & $68(8.3)$ & $19(1.9)$ & $71(12.4)^{*}$ \\
\hline Duodenal ulcer & 10 & $66(5.6)$ & $78(8.8)$ & $23(3.9)$ & $102(21.9)^{*}$ \\
\hline ZES & 10 & $\begin{array}{l}392 \dagger \\
(133-27720)\end{array}$ & $\begin{array}{l}1112^{*} \\
(349-36670)\end{array}$ & $32(7.3)$ & $107(14.6)^{*}$ \\
\hline Atropic gastritis & 10 & $\begin{array}{l}664 \dagger \\
(215-1670)\end{array}$ & $\begin{array}{l}376^{*} \\
(151-1090)\end{array}$ & $30(6.1)$ & $103(21.8)^{*}$ \\
\hline
\end{tabular}

${ }^{*} P<0.01$ vs basal (Wilcoxon test); $† P<0.01$ vs controls (Mann-Whitney test).

secretin administration. Patients with histologically proven atropic gastritis had elevated fasting gastrin levels that decreased after secretin administration.

Secretin (Sekretolin, Hoechst, Frankfurt, Germany) $2 \mathrm{U} / \mathrm{kg}$ body weight was given i.v. over $1 \mathrm{~min}$ at time 0 . All tests were started between 0900 and $1000 \mathrm{~h}$ after an overnight fast and one hour of bed rest. Blood was taken from a forearm venous cannula kept patent by slow saline infusion. Samples were collected in ice-chilled polypropylene tubes containing EDTA $(1 \mathrm{mg} / \mathrm{ml})$ and aprotinin $(500 \mathrm{KIU} / \mathrm{ml}) 30 \mathrm{~min}$ and immediately before the secretin injection and at 2, 5, 10, 15, and $30 \mathrm{~min}$ after the secretin injection. Plasma was separated immediately by centrifugation at $4^{\circ} \mathrm{C}$ and stored in aliquots at $-80^{\circ} \mathrm{C}$ until assayed.

Gastrin and PP were measured by radioimmunoassay using commercially available kits (Incstar Corporation, Stillwater, MN, USA, and Peninsula Laboratories, Inc., Belmont, CA, USA) as previously described (9). The upper limits of our normal ranges (mean +3 S.D. of 100 healthy subjects aged 18-78 years) were $110 \mathrm{ng} / \mathrm{l}$ for gastrin and $57 \mathrm{pmol} / \mathrm{l}$ for PP.

Results were expressed as means \pm s.E.M., with the exception of gastrin data in patients with ZES and atropic gastritis which were given as median value and range. Statistical analysis of the data was performed by Wilcoxon and Mann-Whitney tests, using Bonferroni's correction for multiple comparisons. Pearson's test was employed to seek correlations between variables. A $P$ value of $<0.05$ was considered significant.

\section{Results}

As shown in Table 1 there were no significant differences in mean fasting PP levels among the different groups of subjects, although the highest values ( 68 and $76 \mathrm{pmol} / \mathrm{l}$ ) occurred in two ZES patients, one of whom had a MEN I. These values were above the upper limit of our normal range ( $57 \mathrm{pmol} / \mathrm{l})$.

Secretin stimulated PP release in all the subjects (Table 1). Peak values were similar in the different groups of subjects and usually occurred $5 \mathrm{~min}$ after injection (range 2-10 $\mathrm{min}$ ).
There were no significant correlations between PP response to secretin, expressed as both $\Delta$ peaks and areas under the curve (AUC), and other variables considered, including subject age, basal PP levels, and gastrin basal levels and AUCs after secretin.

\section{Discussion}

In agreement with previous findings $(4,6,7)$, our results clearly demonstrate that in humans secretin, given at pharmacological doses as an i.v. bolus, is a powerful stimulus for PP release. This does not imply that secretin plays a role in the physiological control of PP secretion. Indeed, conflicting and even negative data have been reported when secretin was given at submaximal doses or as slow infusions $(2,5,8)$.

In our ZES patients the secretin/basal PP ratio was $4.2 \pm 0.95$, a figure similar to that of $2.7 \pm 0.36$ obtained by Rigaud et al. (2) in 26 untreated ZES patients. This response, however, cannot be regarded as a paradoxical one, since we found similar increments in patients with normo- and hypergastrinemia, and also in healthy subjects. Moreover, there was no significant difference in the PP pattern between patients with and without MEN I, the peak values being $121 \pm 19.9$ and $98 \pm 20.9 \mathrm{pmol} / \mathrm{l}$ respectively.

High PP fasting levels have been reported in 10-77\% of patients with gut apudomas (10-14) and it has also been suggested that the finding of elevated peptide levels could be a marker for endocrine pancreatic tumors in patients with MEN I $(10,13,15)$. In our series $20 \%$ of ZES patients showed basal PP levels which were definitely supranormal, but lower than $300 \mathrm{pmol} / \mathrm{l}$, which is the suggested cut-off value for endocrine pancreatic tumors (12). Moreover, only one out of our four MEN I patients had elevated plasma PP levels, thus confirming the suggestion that high fasting plasma PP levels are a relatively insensitive marker for endocrine pancreatic tumors $(13,14)$.

The secretin test does not improve the diagnostic sensitivity of PP determination but the plasma PP response to a meal can be exaggerated in MEN I patients (15). On the other hand, it is obvious that in MEN I 
patients without clinical evidence of gut apudomas the finding of high fasting or postprandial plasma PP levels must direct imaging studies.

\section{Acknowledgements}

This work was supported in part by Murst (60\%) and by Associazione Amici della Gastroenterologia del Padiglione Granelli.

\section{References}

1 Meko JB \& Norton JA. Management of patients with ZollingerEllison syndrome. Annual Review of Medicine 199546 395-411.

2 Rigaud D, Accary JP, Mignon M \& Bonfilis S. Abnormal pancreatic polypeptide release by secretin infusion in Zollinger Ellison syndrome. Digestive Diseases and Science 198429 696-702.

3 Strodel WE, Vinik AI, Lloyd RV, Glaser B, Eckhauser FE, FiddianGreen RG et al. Pancreatic polypeptide producing tumors. Archives of Surgery 1984119 508-514.

4 Adrian TE, Besterman HS, Cooke TJC, Faber RG, Bloom SR, Barnes AJ et al. Mechanism of pancreatic polypeptide release in man. Lancet 19771 161-163.

5 Schwartz TW \& Rehfeld JJ. Mechanism of pancreatic polypeptide release. Lancet $19771697-698$

6 Glaser B, Vinik AI, Sive AA \& Floyd JC. Plasma human pancreatic polypeptide responses to administered secretin: effects of surgical vagotomy, cholinergic blockade, and chronic pancreatitis. Journal of Clinical Endocrinology and Metabolism 198050 1094-1099.

7 Diem P, Redman JB, Abid M, Moran A, Sutherland DER, Halter JB et al. Glucagon, catecholamine and pancreatic polypeptide secretion in type I diabetic recipients of pancreas allografts. Journal of Clinical Investigation 199086 2008-2013.
8 Rasmussen MH, Carstensen H, List S, Schwartz TW \& Hilsted J. Impaired pancreatic polypeptide response to meal in type 1 diabetic patients: vagal neuropathy or islet cell disfunction? Acta Endocrinologica 1993128 221-224.

9 Corbetta S, Pizzocaro A, Peracchi M, Beck-Peccoz P, Faglia G \& Spada A. Multiple endocrine neoplasia type 1 in patients with recognized pituitary tumours of different types. Clinical Endocrinology 199747 507-512.

10 Friesen SR, Kimmel JR \& Tomita T. Pancreatic polypeptide as screening marker for pancreatic polypeptide apudomas in multiple endocrinopathies. American Journal of Surgery 1980139 $61-71$.

11 Öberg K, Grimelius L, Lundqvist G \& Lörelius LE. Udpate on pancreatic polypeptide as a specific marker for endocrine tumours of the pancreas and gut. Acta Medica Scandinavica 1981210 145-152.

12 Lamers CBHW \& Diemel M. Basal and post atropine serum pancreatic polypeptide concentrations in familial multiple endocrine neoplasia type I. Journal of Clinical Endocrinology and Metabolism $198255774-778$.

13 Schwartz TW. Pancreatic polypeptide: a hormone under vagal control. Gastroenterology 198385 1411-1425.

14 Adrian TE, Uttenthal LO, Williams SJ \& Bloom SR. Secretion of pancreatic polypeptide in patients with pancreatic endocrine tumors. New England Journal of Medicine 1986315 287-291.

15 Skogseid B, Öberg K, Benson L, Lindgren PG, Lörelius LE, Lundqvist $\mathrm{G}$ et al. A standardized meal stimulation test of the endocrine pancreas for early detection of pancreatic endocrine tumors in multiple endocrine neoplasia type 1 syndrome: five years experience. Journal of Clinical Endocrinology and Metabolism 198764 1233-1240.

Received 2 December 1998

Accepted 19 February 1999 